\title{
Implications for Supporting Marginalized Job Seekers: Lessons from Employment Centers
}

\author{
TAWANNA R. DILLAHUNT, University of Michigan, School of Information, USA \\ MATTHEW GARVIN, University of Michigan, School of Information, USA \\ MARCY HELD, University of Michigan, School of Information, USA \\ JULIE HUI, University of Michigan, School of Information, USA
}

\begin{abstract}
Rapid changes in technology are expected to limit the availability of decent work for millions of people worldwide. This particularly disadvantages socially and economically marginalized job seekers who are already being pushed into lower-wage precarious work with increasing levels of job insecurity. While the number of employment support tools that match job seekers to employers has been growing, marginalized job seekers still significantly rely on physical employment centers that have a track record of supporting the specific needs associated with marginalization and economic constraints. We drew from prior HCI and CSCW literature uncovering the employment and technology-related challenges that marginalized job seekers face and from the Psychology of Working Theory to frame our research questions and results. To complement this prior work, we investigated how employment center staff work with marginalized job seekers and moderate factors to securing decent work. We found in an interview of 21 employment center staff-career advisors and business services coordinators-that they performed significant work to prepare and encourage marginalized job seekers in applying to positions, while also training employers to be more inclusive and openminded. Career advisors worked directly with job seekers to connect them with external resources, provide encouragement, strategize long-term goals, and mitigate feelings of stigma. Business services coordinators worked directly with employers to prepare job positions and employee support programs. Drawing from the expertise of employment centers, we contribute a framework for designing employment support tools that better serve the needs of marginalized job seekers, and outline tangible design implications that complement the support these organizations provide.
\end{abstract}

CCS Concepts: • Human-centered computing $\rightarrow$ Empirical studies in HCI.

Additional Key Words and Phrases: Employment, job seekers

\section{ACM Reference Format:}

Tawanna R. Dillahunt, Matthew Garvin, Marcy Held, and Julie Hui. 2021. Implications for Supporting Marginalized Job Seekers: Lessons from Employment Centers. Proc. ACM Hum.-Comput. Interact. 5, CSCW2, Article 324 (October 2021), 24 pages. https://doi.org/10.1145/3476065

\section{INTRODUCTION}

Technological advances have transformed and continue to transform the labor market. While this presents a wide number of opportunities for career success, these opportunities are often not accessible to everyone $[12,92]$. Experts predict that technological changes, including the evolution

Authors' addresses: Tawanna R. Dillahunt, University of Michigan, School of Information, USA, tdillahu@umich.edu; Matthew Garvin, University of Michigan, School of Information, USA, mgarvin@umich.edu; Marcy Held, University of Michigan, School of Information, USA, mheld@umich.edu; Julie Hui, University of Michigan, School of Information, USA, juliehui@umich.edu.

Permission to make digital or hard copies of all or part of this work for personal or classroom use is granted without fee provided that copies are not made or distributed for profit or commercial advantage and that copies bear this notice and the full citation on the first page. Copyrights for components of this work owned by others than the author(s) must be honored Abstracting with credit is permitted. To copy otherwise, or republish, to post on servers or to redistribute to lists, requires prior specific permission and/or a fee. Request permissions from permissions@acm.org.

(c) 2021 Copyright held by the owner/author(s). Publication rights licensed to ACM.

2573-0142/2021/10-ART324 \$15.00

https://doi.org/10.1145/3476065

Proc. ACM Hum.-Comput. Interact., Vol. 5, No. CSCW2, Article 324. Publication date: October 2021 
of digital platforms and automation, will limit the availability of decent work for millions of people worldwide [9]. Indeed, socially and economically marginalized job seekers are at a particular disadvantage [14]. These job seekers are being pushed into lower-wage precarious work with increasing levels of job insecurity $[13,89,96]$.

$\mathrm{HCI}$ and CSCW have a growing body of literature that identifies technology's opportunities and shortcomings in supporting marginalized groups' economic mobility. This research has noted: (1) the resulting decline in traditional jobs $[38,52]$ and the uncertain working conditions of the digital sharing economy (invisible, part-time, and precarious work [4, 81]); (2) how resource-constrained entrepreneurs are using (or not using) technology to make a living [6, 32, 62, 90]; and (3) challenges in designing interventions to support marginalized job seekers including those who are homeless $[58,59]$, from low-resource areas [35, 101], and with autism [57]. While this literature calls attention to the complexity of fostering economic mobility, the perspectives of employment centers-those who have found success in supporting marginalized job seekers-have largely been missing from this research [15, 20,21, 33, 74, 100], and limits our ability to have a comprehensive perspective on how to better support them. Thus, our work contributes a complementary perspective to prior work and situates the role of employment centers and the support they provide in the literature.

We follow Duffy et al.'s definition of marginalization in the context of work, which "represents the relegation of people (or groups of people) to a less powerful or included position within a society, experiencing marginalization as a critical barrier to securing decent work" [41, p.132] The International Labor Organization (ILO) [95] has helped to advance our understanding of decent work, which focuses on defining acceptable working conditions as it relates to human rights [14]. Thus, our study focuses on the ecosystem to support job seekers who are in or near poverty, who experience discrimination and marginalization [41], and who likely face longer-term unemployment.

Employment centers have been successful in reducing local unemployment, particularly in neighborhoods with fewer resources and limited opportunities [66]. These centers, which staff experts at job placement and navigating marginalization [54], aid up to 15 million job seekers per year by providing them with information about the characteristics of available jobs and the costs and benefits of enrolling in training programs [64]. If technology were to moderate the impact of marginalization and economic constraints on acquiring decent work, we argue that it is crucial to understand the perspectives of those who serve marginalized job seekers in employment centers Therefore, we conducted an empirical study that consisted of 21 semi-structured interviews with employment center staff-11 career advisors and 10 business services coordinators-to explore how they moderate access to decent work for marginalized job seekers.

We used the Psychology of Working Theory, which outlines the key elements for securing decent work [12], to help frame our results. Decent work includes adequate earnings, hours that allow for rest and free time, a safe work environment, healthcare access, and aligns with social and family values [40, 95]. In using this theory, we found that career advisors and business services coordinators helped to not only secure decent work for marginalized job seekers, but find better talent for employers. Career advisors worked directly with job seekers to connect them with external resources, provide encouragement, strategize long term goals, and mitigate feelings of stigma. Business Services Coordinators, on the other hand, worked directly with employers to prepare more inclusive job positions. Together, they addressed the majority of elements needed to secure decent work, as outlined by the Psychology of Working Theory. We discuss how these empirical findings suggest implications for designing more inclusive technologies meant to support job search and employment. Our contributions, which fill a gap in CSCW, HCI, and workforce development literature $[15,20,21,33,74,100]$ include: 
- An empirical understanding of how career advisors and business services coordinators support marginalized job seekers;

- A framework, informed by the Psychology of Working Theory, for what to take into account when designing systems that aim to support marginalized job seekers;

- Tangible design implications that complement and amplify the work of employment centers.

\section{PSYCHOLOGY OF WORKING THEORY}

To situate our work, we introduce the Psychology of Working Theory (PWT), which centers on the goal of decent work [41] (See Figure 1). For context, the practice of career guidance has foregrounded issues of career choice and development. While this has been helpful to students and clients, it does not take into account those with little to no choice in their work options [82]. The use of PWT as a theoretical framework is innovative, and thus has not been widely adopted by job centers. PWT challenges earlier theories that were based on the assumption that job seekers, and those looking to develop their careers, did not face significant social or economic challenges [41]. Recent HCI literature and others, as it relates to marginalized job seekers and precarious workers, in fact breaks such assumptions. Thus, we focus on contextual predictors because much of the proposed interventions from CSCW and HCI, as we discuss later, primarily emphasize personal factors like career adaptability, or one's capacity to cope with changing work environments [85], within the job seekers' control.

Our analysis focuses on four moderators that aim to alleviate or buffer the effect of economic constraints and marginalization, the two contextual variables that are hypothesized to predict securing decent work (see Moderators and Predictors in Figure 1). Our model is an abridged version of the full model, which includes empirically supported links from economic constraints and marginalization to the contextual variables of work volition and career adaptability. These two contextual variables are also empirically linked and hypothesized to predict securing decent work. Since the development of the model, research has begun building empirical evidence for its utility $[5,42,94]$.

2.0.1 (Contextual) Predictors. People experiencing contextual factors like greater marginalization and economic constraints are less likely to secure decent work. Duffy et al. describe these factors independently for "conceptual clarity" [41, p.131] and acknowledge that they intersect and interact in essential ways [24, 88]. Marginalization is described as assigning people or groups of people to inferior positions within a society (e.g., by race, social class, gender, ability, etc. and the intersections of these factors). Economic constraints impact one's ability to access or invest economic resources that make it easier to achieve those milestones necessary to develop one's career (e.g., education, internships) and are explained by limited financial resources like income or wealth but also social and cultural capital [41]. Those who have access to such resources might have easier access to educational opportunities (like college or extracurricular activities) that foster cognitive stimulation and pave the way for perceived "fit" in interviews and workplace environments, and thus "career success" [41].

2.0.2 Moderators. In the Psychology of Working Theory, the four moderator variables (proactive personality, critical consciousness, social support and economic conditions) can intensify or alter the strength or direction of the relation between the predictor variables (economic constraints and marginalization) and one or more of the outcomes associated with securing decent work, such as work fulfillment or well-being. In our investigation, we pose the following research questions: 


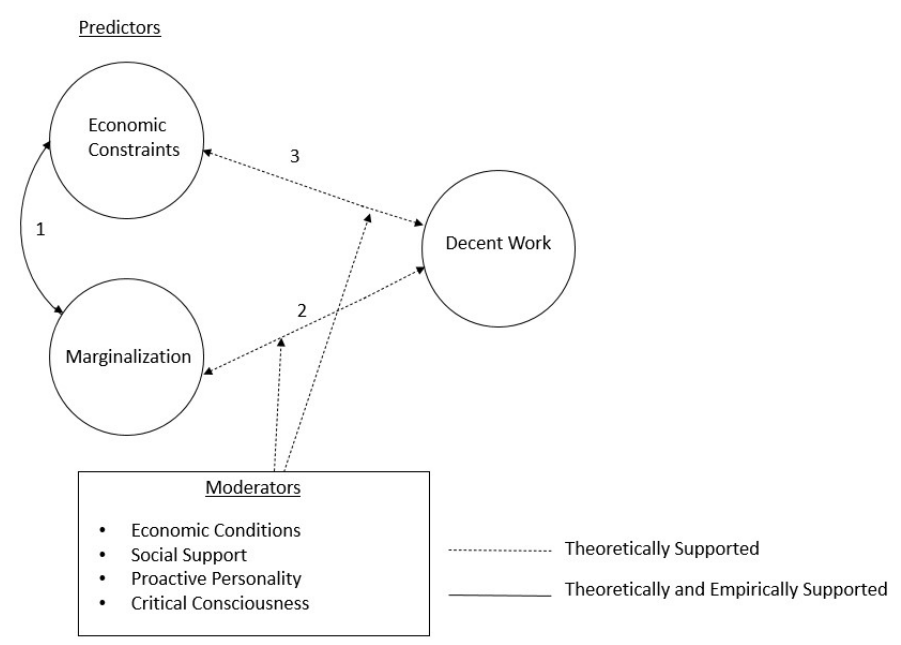

Fig. 1. Psychology of Working Theoretical Model [41].

- RQ1: How do employment centers, through the work of career advisors and business services coordinators, address moderators to securing decent work (i.e., economic conditions, social support, proactive personality, and critical consciousness)?

- RQ2: How might the work of employment centers inform implications for designing employment support tools that are more inclusive to marginalized job seekers?

Economic conditions and social support have been discussed extensively in career development literature. Economic conditions, such as the number of jobs available, unemployment rates, and training opportunities significantly impact a job seeker's ability to find decent work [95]. Social support refers to the extent to which we feel support from our friends, family, and broader community for managing the challenges associated with marginalization and economic constraints [22]. Having high levels of social support helps to diminish the impact of financial stress on academic performance and well-being [41]. Proactive personality refers to one's resilience in the face of hardship. People with proactive personalities show initiative, search for opportunities, and maintain tenacity to bring out meaningful change [8]. Having a proactive personality is related to career success, and proactive people are well suited to pursue boundaryless careers [49]. Finally, the PWT propositions that a fourth moderator, critical consciousness [47, 98], will also act as a buffer [41]; however, it is a lesser explored moderator in the employment literature. The evidence is mixed with respect to the relationship between critical consciousness and progress in career development [26]. Prior work suggests it is associated with engagement in career development, vocational expectations, and career commitment among marginalized youth [26, 27]. While this past work analyzed critical consciousness as a direct predictor (main effects) of these outcomes, Duffy et al. specifies critical consciousness as a moderator that weakens the negative impact of economic constraints and experiences of marginalization [41] to securing decent work.

Critical consciousness refers to the "capacity to recognize and overcome sociopolitical barriers" [26, p.220]. Consisting of critical reflection, political efficacy, and critical action, Watts, Griffith, and Abdul-Adil refer to critical consciousness as the "antidote to oppression" [99]. Critical reflection 
refers to the critical analysis of structural and social contributions to societal inequities. Political efficacy refers to one's perceived capacity to effect political and social change, and critical action refers to actions, made individually or collectively, to change perceived inequalities. People who are critically conscious have the capacity to understand and decipher their social conditions [44], which expands their commitment to confront pervasive injustice $[53,98]$, and has been shown to improve political engagement and academic achievement [19].

\section{RELATED WORK}

We describe prior non-profit and career development research and conclude with the state of related $\mathrm{HCI}$ research in the context of PWT.

\subsection{Non-Profits and Career Development}

Non-profit (employment) centers provide access to career planning, skills and training, and informational resources. These organizations often provide the social support that tends to be inaccessible to unemployed individuals by connecting those experiencing marginalization and economic constraints to labor markets. Previous research has identified dimensions affecting employment outcomes, such as labor market dynamics, the public policy environment (i.e., economic conditions), and social dynamics [50]. Economic conditions that affect employment outcomes for disadvantaged job seekers per past HCI research include limited transportation to work [31, 35, 37] and homelessness $[58,59]$, and policies that slow down or prevent the employment of returning citizens $[77,78,97]$. To address these economic factors, researchers have suggested further investigations of interventions, like the work of employment centers, that provide access to resources to address societal challenges that job seekers face $[33,50]$. However, the organizations' role in employment among marginalized job seekers is under-researched [15, 20, 21, 74, 100]. Thus, our research investigates how such organizations address moderators to securing decent work, and takes a CSCW lens to identify how such practices could inform the design of employment support tools.

Much of the past literature investigating the role of employment organizations in career development discusses their role in providing ICT training [50]. However, in a study of over 70 NGOs across 30 countries worldwide, researchers concluded that while ICT skills were important, they were, on their own, insufficient for members of disadvantaged groups to improve their socio-economic standing. They found indirect benefits of providing ICT skills training to be helpful for expanding social networks and language acquisition specifically, which was particularly beneficial to immigrant women [50]. We argue that the perspectives of employment centers could lead to a more comprehensive understanding of how to better support job seekers experiencing marginalization and economic constraints in the digital age. We complement and extend the existing research in this area with an investigation of the roles and experiences of people working in employment centers, and situate our findings in the Psychology of Working Theory.

\subsection{Career Development in HCI}

Recently, HCI and CSCW work has aimed to support the needs of economically constrained job seekers and entrepreneurs (particularly those who are transitioning to entrepreneurship). We extend these efforts to inform the design of technologies to buffer the employment difficulties faced by marginalized groups including homeless youth [58, 59], returning citizens [77, 78], and low-resource job seekers $[28,34,50,65,101]$. Existing researchers have developed tools to support skill development through crowdsourced mentorship [84, 91], and online help seeking by leveraging mechanisms of cognitive apprenticeship [61]. Suzuki et al. developed Atelier, an Upwork-based micro-internship platform. Atelier assigned experienced mentors to support novice workers in 
online task completion [91]. While this previous work initiated connections with mentors on behalf of the learner, others described how to scaffold the work novices must do in order to connect with potential experts themselves [61]. In these two cases, the novice/expert relationship was facilitated to support connections for those who had weaker professional networks. As mentioned earlier, one study found that immigrant women benefited from language acquisition and expanded networks acquired through ICT skills training, in addition to learning ICT skills.

Social support and capital are important for helping low-resource job seekers to secure employment via job referrals and learning inside knowledge related to available positions [101]. However, while making social connections is crucial, it is not always easily accessible, especially among individuals who are unemployed and experiencing poverty. Because these individuals often have limited contact with employed individuals, they also lack connections to people to connect them to employment [86]. Wheeler and Dillahunt found that technology plays a role in supporting the job process by helping low-resource job seekers (1) learn about jobs, (2) apply to jobs, and (3) secure job offers [101]. They found that these tools supported such job seekers in providing job information, but were less effective at educating job seekers about the importance of those social connections.

A review of the challenges and needs of job seekers experiencing marginalization revealed that past employment concepts and interventions have aimed to provide social support by connecting job seekers to social resources and provided tools to access expert feedback [33]. One such system, Review-me, aimed to bridge the limited access low-resource job seekers had to individuals who could provide them with résumé feedback [28]. Another system, DreamGigs, provided low-resource job seekers with information about the career-related skills that they would need to reach their ideal job, and provided a pathway for how to go about reaching this job [34,72], which could potentially enhance career adaptability and work volition. In all, these technologies supported the moderators social support and to an extent economic conditions. As informed by the productive practices of employment centers, our investigation leverages the Psychology of Working Theory to design and evaluate employment support tools across the various moderators to decent work in order to better serve marginalized job seekers.

\section{METHODS}

We begin by providing background information about the organization and staff that we interviewed. We also provide political and administrative contexts. This is important as it provides information to enable those outside of our specific geographic and political context to appreciate our work more fully. We conclude with our participants and recruitment method, and details about our data analysis.

\subsection{Background Context}

Our study took place between September 2017 and May 2018 among local job centers in a Midwestern, state in the United States (U.S.). The unemployment rate of our study location at the time was $4.0 \%$ and slightly higher than the rest of the U.S. The three key industries in the region included manufacturing, which had experienced a significant reduction in the past decade; agriculture, and tourism, both of which experience seasonal shifts. Overall, local unemployment rates had fallen since the Great Recession ended in 2010. However, workers still struggled financially to afford basic necessities such as child care, housing, and transportation [3]. Therefore, job seeking was a top priority. Sixty-one percent of all jobs in the state at the time paid less than $\$ 20$ per hour, and gaps in wages were widening [3]. These gaps varied depending on the location and number of employees at a specific workplace. Other influencing factors included race/ethnicity, education, ability, gender, sex, and sexual orientation of workers. These personal characteristics reflected those who were most likely to be unemployed at the time $[16-18,75]$. For instance U.S. unemployment among Black,

Proc. ACM Hum.-Comput. Interact., Vol. 5, No. CSCW2, Article 324. Publication date: October 2021. 
Indigenous, and people of color experiencing higher levels of unemployment than White Americans [75]; those with a high school diploma or less [17] are more likely to face unemployment; and people with disabilities are much more likely to face unemployment than those with no disability [18]. In line with statistics showing that those who experiencing marginalization were those who are most likely to be unemployed, we found that the employment center served proportionately more of these job seekers (approximately 70\% at the time of our study), which reflects past findings [66]. To receive unemployment benefits, job seekers had to have been laid off, left or quit their job for dangerous work conditions or discrimination, or fired for not having the necessary job skills. Not everyone received unemployment benefits and these benefits fluctuated depending on the political context and the economy. Certain benefit programs, for example, required job seekers to meet with a career advisor to receive benefits.

\subsection{Participants and Recruiting}

We contacted a local non-profit organization that was a member of the American Job Center network. The network was established under the Workforce Investment Act of 1998 to provide access to education, training, and employment services from multiple agencies at a single location. The organization consisted of three local job centers that collectively served more than 2,500 employers in the region annually. We contacted the organization via email and the organization agreed to send our recruitment emails to their staff members on our behalf. The $40+$ staff members consisted of career advisors, who worked directly with job seekers to help them find employment, and business services representatives/coordinators, who worked directly with company recruiters. Due to concerns of anonymity, we do not report our participants' demographic information such as race, age, gender, or organization tenure. We did not collect information regarding participants' level of education and training; however, extensive preparation is needed to hold such positions. While very few people might thrive with on-the-job training most of these occupations require graduate school [79].

Participants used the terms business services representatives and coordinators interchangeably but we use business services coordinators throughout this article for consistency. Career advisors and business services coordinators deal with many requests in a poor economy, and few when it's doing well, making advanced preparation difficult. The career advisors and business services coordinators interviewed had worked in different economic and political climates, meaning that they served a wide variety of populations, which reflected job sector changes. We recruited a total of 21 employment center staff-11 career advisors and 10 business services coordinators.

\subsection{Procedures}

All interviews were conducted on site at the employment center. Interviews provided insight into how career advisors and business services coordinators work together to place job seekers in employment, and what some of the pain points were in this process. We asked career advisors to describe their roles, challenges working with different types of job seekers, as well as logistical questions like how often career advisors communicated with job seekers and what technologies they used to do so. For instance, we asked the following questions: Can you describe the most recent time you worked with a job seeker to secure a new job? How long did the process take? What was most difficult about this process? How did you communicate with the job seeker, and how often? Did this most recent experience differ from your other experiences working with job seekers in any way? If so, how? When interviewing business services coordinators, we inquired about their typical process when working with companies, the main challenges they faced in the relationship, and how they helped companies connect with the right job seekers. For example, we asked, Do you think that qualifications listed in job descriptions accurately represent what companies are actually looking for? If 
no, how do you help companies fill these gaps? Could you describe the most recent time you connected a job seeker with a recruiter? What was easy or difficult about this process? These questions encouraged career advisors and business services coordinators to reflect deeply on specific experiences, which then allowed us to probe further about their reasoning and processes.

Participation was voluntary and we did not provide financial compensation to participants. Because participants interviewed while working for the partnering organization, we were unable to doubly-compensate them. Instead, we provided coffee and breakfast upon presenting the initial results. Our institutional review board approved this study and all stakeholders signed consent forms. All interviews were recorded, professionally transcribed, and lasted an average of 50 minutes $(\mathrm{SD}=15)$.

\subsection{Data Analysis}

Two researchers met initially to inductively conduct open-coding analysis after an initial round of data familiarization [83]. We identified broad themes around the types of marginalization job seekers faced, the responsibilities of career advisors and business services coordinators, and the overall process of applying to jobs. Theoretical saturation was reached when no new themes emerged as we continued to add more data to the analysis. We then reviewed various theories that outlined variables to securing employment $[41,48]$. To enhance rigor and increase the trustworthiness of the results of our analysis, we member checked $[10,70]$ the results of our analyzed data with career advisors, business services coordinators, and other key staff. The purpose of member checking was to validate results by seeking disaffirming voices (objectivism) and open up opportunities to add data (constructivism) [10,70]. Overall, there were a few points of clarification made in the data regarding process; however, there was overall consensus in the findings. We ultimately chose to analyze our findings using the Psychology of Working Theory [41] because it was the only theory that took into account the unique challenges that marginalized job seekers faced.

In this next round of analysis, we performed provisional coding, which begins with an initial list of codes generated from related work suggesting what might be found in the data, and also allows for the addition of new codes [83]. Thus, in order to address our research question-How do employment centers, through the work of career advisors and business services coordinators, address moderators to securing decent work?-we used PWTs moderators (economic conditions, social support, proactive personality, and critical consciousness) as initial codes.

After analyzing the data according to these moderators, we then performed a third round of open coding which identified what techniques career advisors and business services coordinators used to address these moderators. The second and third rounds coding were completed when no new themes or topics emerged around PWT moderators as we added new data. The final structure of our results uses moderators identified in PWT as the primary sections, while sub-themes describe how career advisors and business services coordinators facilitated these moderators. In this process, we identified a potential new moderator to decent work-feelings of stigma-which was not addressed in PWT. People affected by marginalization and economic constraints face a variety of barriers and challenges that negatively impact their ability to find and secure decent work. Before presenting our results, we provide context to the forms of economic constraints and marginalization job seekers faced and ways in which advisors and business services coordinators mitigated these barriers.

\section{RESULTS}

We begin our findings with an overview of employment barriers described by our participants to situate our work into prior research of job seekers themselves and for contextual purposes. Our findings then outline the background work needed to support marginalized job seekers, as theorized by the Psychology of Working Theory [41]. Career advisors and business services 
coordinators worked with job seekers and employers respectively to address PWT moderators to decent work-economic conditions, social support, and proactive personality. Our findings point out how career advisors and business services coordinators perform significant effort beyond just matching job seekers to open positions. When job seekers face challenges from marginalization and economic constraints, career advisors and business services coordinators step in to provide resources and support that more socio-economically stable job seekers might take for granted.

However, we did not find evidence for the PWT moderator of critical consciousness-one's ability to recognize and overcome socio-political barriers [26]. We do uncover a potential new moderator, feelings of stigma, in which we describe how career advisors re-frame negative personal and public perceptions (e.g. stigma of being an ex-offender, having employment gaps) to increase marginalized job seekers' likelihood of sticking with their job search and recovering from rejection.

\subsection{Overview of Employment Barriers}

According to career advisors, when job seekers enrolled to work with them, they completed intake forms, which captured their current needs via a checklist of common employment barriers. This enabled career advisors to find supporting programs for the job seekers. The list of items included housing, transportation, having criminal backgrounds, and mental health challenges, although clients, according to career advisors, were reluctant to select mental health. Still, in other cases, clients might have thought they faced one issue, but after talking with the career advisor, learned about others they were facing, or would later face. Career advisors used the intake form as a starting point and followed-up with informational interviewing to identify specific needs and determine which resources were available to support the client's path to decent work. Finding ways to assist with job seekers' unique situations was a key responsibility of career advisors (CAs) and business services coordinators (BSCs) as noted in the quote below ${ }^{1}$ :

Each person comes in with their own unique barrier and how do we assist them with solving that barrier? That probably takes the most work than anything else. - CA8

Overall, we found the two most common barriers to employment to be housing insecurity and the lack of transportation. Housing was perhaps the largest barrier throughout the region, whereas transportation issues were most prevalent in rural areas or urban/suburban areas without reliable public transit. Moreover, housing insecurity was most common across different groups, from marginalized youth, returning citizens, and single moms.

Having a criminal background was another common barrier to employment. And, unless they had social support from friends and family, many returning citizens faced both housing insecurity and transportation issues. The Department of Corrections directs returning citizens to job centers to help support their process of re-entry. According to career advisors, returning citizens typically don't know what to do and are afraid. One of the career advisors, who told us that he was a returning citizen himself, specializes in helping returning citizens to become job-ready. He stated,

When the Department of Corrections cut the re-entry program, and they're still doing this, they just tell people when they're released or discharged to come to us. - CA3

Among the many challenges they already face, this career advisor noted that many positions that returning citizens would otherwise be qualified for, are unavailable to them simply by virtue of having a criminal background. In healthcare and IT for example, many positions require a security clearance. Even a handful of cleaning companies would not let their employees go into a business or home with a criminal background. Sex offenders are not allowed to use computers at all, regardless of whether or not technology was a component of their offense. Sometimes, even if the returning

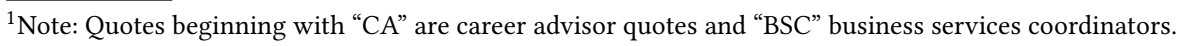


citizen can find a "felony friendly" employer, these employers typically offer low wages and poor working conditions.

\subsection{Economic Conditions}

Career advisors and business services coordinators worked together to help job seekers overcome their existing economic conditions. Career advisors connected job seekers to external resources, like job training and financial assistance programs, even sometimes acting as intermediaries, guiding the individual through the process of applying. Business services coordinators helped to create a better working environment by helping employers develop job calls and employment policies that were more inviting and inclusive.

5.2.1 Connections to external resources. According to career advisors, knowing which resources to apply for, or even knowing what public support existed, was a daunting task for job seekers experiencing marginalization. Career advisors served as intermediaries by educating job seekers on their options and helping them apply and get connected. For example, if an individual is homeless or otherwise experiencing housing insecurity, the career advisor identified the best housing program they qualified for, from connecting the job-seeker to a shelter or helping them get processed into subsidized housing. When an individual's barrier to securing employment was related to transportation, career advisors pursued a number of options.

So I would say one to two people a week that comes up...it's like, hey, I've got transportation issues. I'm looking at the paperwork going like, you have skills that I'm sure an employer will hire you, but how you goin' to get there? Is it on the bus line? If it's not on the bus line can we provide maybe, pay for Uber for something initially to get you back until you're actually making some money and maybe meeting somebody at your job location that you could carpool with. Or maybe you're making enough money to invest in transportation. CA8

In under-resourced communities, people often rely on each other to meet unanticipated and last minute needs, like a ride to the store or job [37]. In this case, if a job seeker is unable to secure car pooling from their personal network, employment centers can step in to provide this support until the client's situation is more stable. In addition, through collaborations with business services coordinators, the career advisor might be aware of certain employers who work with employees to coordinate alternative transportation options. In some situations, depending on funding, the career advisors may be able to directly pay for car repairs, ride-sharing fares (Uber, Lyft), or connect the individual to an external program that will help buy them a car.

In recent years, career advisors have also forged alliances with the local courts and criminal justice system. They work with public defenders and the prosecutors office to determine who is eligible for getting their criminal records expunged. Career advisors supported ex-offenders in walking them through the entire process, from pre-screening to determine eligibility, to standing before a judge to get their records expunged. With regard to medical or mental health issues, career advisors did their best to secure financial assistance for those who were unable to work.

Even though the doctor says they can't [work], we are required to have them do job search and other activities to meet requirements [for cash assistance]. They're not excused. Now if you have a mental and physical disability and you have a 30-hour a week requirement and the doctor says you really shouldn't be doing these things, what do we do with these customers? It's very, very hard to get them to meet their requirements on a regular basis. CA4 
In this case, the career advisor worked with the job seeker to overturn a ruling that required this person to work a certain number of hours when they were physically unable. Unfortunately, state and national policies often require individuals with disabilities to meet minimum work requirements to access needed benefits. Working within these constraints, career advisors will refer these individuals to an external organization that caters to their unique needs.

5.2.2 Preparing employers and work conditions. Business services coordinators worked with employers to affect local changes in economic conditions. Business services coordinators described how employers had trouble converting their business needs into a relevant job call. Because many of the employers are smaller businesses with no human resources department, business services coordinators must act as an outsourced hiring department that works closely with the employer to draft job descriptions and programs that will attract the right candidate. This setup takes significantly more work than just writing up and posting a description online, and often involves helping to develop job openings, increase pay, organize transportation, and set up flexible work schedules. All of these factors at the individual job level have significant impact on matching job seekers with employers and fostering longer-term retention.

Let's say I have an employer that calls me up and says, 'I've got a job position I need to post.' And we start talking about the job position and I ask him, 'Is it something that somebody had left? Has your business increased? What's going on?' And then I hear, 'Well I've got a lot of turnover.' Well, that starts that whole conversation into a whole different level because now it's why do you have turnover? What kind of things could we look at? $-B S C 8$

This work involves working with employers to set up new programs, like on-the-job training and car pools. Such programs make it easier for marginalized job seekers to on-board and work regularly. Previous literature, as well as our own interview data, highlight that access to basic resources like transportation and skills training are some of the primary factors that affect whether under-resourced job seekers are able to hold a position.

I'm working with one company who knows that transportation is an issue just because [of] where they're located. It's not like they can pick up and move their plant, so what they're doing is they're looking at ways to shuttle workers in. They're doing surveys to find out if they have people in the same area where they will pay for transportation and just have a meetup spot. You go there, and they'll bus shifts in and out, which I think is a phenomenal idea...It stops turnover, or at least cuts down turnover. It saves you money in the long run. Yes, you'll have to foot the bill up front, but you'll get qualified employees that are dependent. -BSC9

Business services coordinators have to explain to employers why investing in these programs both creates a better working environment for their workers and builds a stronger company longer-term. Sometimes this form of convincing is about setting up flexible hours, which is critical for underresourced job seekers who might have significantly more unexpected personal responsibilities than the average middle-class employee.

They're [job seekers] looking for flexibility...I mean I still think I'm old school, I think you need to show up on time, you need to be respectful and all of that. But, if they're taking care of a parent, or those kinds of things, there's so much going on in people's personal lives these days. If companies were a little bit more flexible there and made their employees a little bit more happy, then they might retain employees.-BSC10

Business services coordinators raised employer complaints about unreliable employees who often failed to show up for work or quit unexpectedly. While career advisors might attribute this 
to limited soft skills, employment data points to how additional economic stress on marginalized groups makes it difficult to work consistent hours. Having flexible hours may ameliorate these issues to some extent.

Finally, business services coordinators worked with employers to set fair wages. Many employers had not updated their salaries for years, and lacked the technological capacity to stay updated.

I had a staffing agency manager contact me and ask if I could run a report to show pay rates in the area because she was trying to convince one of the employers that she was working for that the pay rate was too low, so we do those things for employers as well... We do wage data, and labor market information, and that kind of stuff. That information changes quarterly.- BSC9

Both business services coordinators and career advisors expressed that minute differences such as an increase of 50 cents per hour at one job could convince people to change companies, which is why it is critical that business services coordinators help employers stay updated on wage data business services coordinators emphasized that they did not have the final say in setting the wage for a newly posted job, but they at least had significant convincing power through the data they compiled. In the end, employers want to attract and retain quality workers long term to create an attractive work environment and salary.

\subsection{Social Support}

Social support-"the degree to which individuals feel supported from their family, friends, significant others, and the broader community," [41, p.137]-helps individuals cope with everyday stress and adversity [23]. Marginalized job seekers who suffer from lack of social support may turn to employment centers to receive the resources and connections they lack from their own personal networks.

5.3.1 Fostering self-efficacy and resilience. Career advisors express the importance of voicing their commitment to helping job seekers, no matter their social circumstances. Although these conversations may not provide tangible support, they provide the emotional social support needed to apply to multiple jobs and deal productively with rejections. Oftentimes, job seekers might not be getting this kind of social support from friends and family, and benefit from hearing positive feedback and encouragement from an employment professional. A career advisor describes how he provides social support to returning citizens on the job market.

I start off by helping the offenders realize they're not alone because we can feel really isolated, like it's just us...So, help them realize they're not alone. Help the person realize, it's all about their skill set. -CA3

For returning citizens, social support from career advisors can be critical to successful re-entry as an individual's professional network may be limited after being isolated. Applying to public assistance programs and to jobs can be a long and tedious process, often requiring significant paperwork or entanglements with bureaucracy [45].

This guy, he wants to work, but his effort in these applications was just slipping. I'm like, 'I want you to reapply and I want to sit down with you and do the application with you because there's no reason why you shouldn't have an interview...You have so much customer service experience, you've worked a food [service], you've done cash handling. You have all the experience they're looking for. You just didn't do your application right.' I realized after that happened, I needed to somehow find more time in my schedule to do that with clients. -CA5 
Career advisors remind job seekers of their assets and continuously encourage them to keep trying despite setbacks. In this case, the career advisor explained how he walks the client through re-writing his application in order to highlight the skills for that particular position. Overall, career advisors filled the gaps in social support that encouraged marginalized job seekers to follow through with the tedious and draining search process.

\subsection{Proactive Personality}

Having a proactive personality-"a disposition toward taking personal initiative to influence one's environment”[69, p.395]-can help job seekers overcome the effects of marginalization and economic constraints. Maintaining a proactive personality is particularly difficult when dealing with marginalization and economic constraints because one has to constantly keep trying despite constant and systemic setbacks. While job search tools, like Indeed, can help job seekers identify potential occupations and open positions, we found that career advisors performed additional interpersonal work to help job seekers seed a sense of initiative through strategizing immediate next steps, seeking additional job information, and long-term planning.

When marginalized job-seekers enter the program, they are often characterized by a sense of urgency that one career advisor described as, "the house is on fire." This means that they are in a state of crisis, "needed a job yesterday", and are reacting to their short-term situation rather than proactively seeking decent work to satisfy long-term needs and goals. Career advisors work with these individuals to not only improve their short-term situation, but to also establish a long-term vision of where they want to end up. Career advisors engage in a dialogue with the individual to better understand their interests and values, triangulating this with prior skills, experience, and the needs of the labor market to create a map from start to finish with actionable goals for the job-seeker to follow.

5.4.1 Strategizing immediate next steps. Career advisors used a range of tools and strategies to help job seekers consider possible employment opportunities. Because people primarily consider careers that they grew up around [80], career advisors help job seekers identify a range of additional jobs and plan out next steps. For instance, career advisors first directed job seekers to O*NET’s online career center that suggested other jobs based on the job seeker's interests. Then, once the job seeker narrowed down their options, the career advisor talked them through how to acquire the needed skills and certifications.

I have one young lady, she wants to own her own daycare. But, I let her take that [O*NET's My Next Move] quiz, and she also saw that 'Oh, I could be a midwife. That could be something.' And like opening up the possibilities. I was like, 'How hard do you want to work? Do you want to get your Master's? Do you want to stop here?' She's like, 'I could see myself getting my Master's.' Okay, if you get your Master's, this is saying you could possibly be a midwife. She's like, 'I never thought of that before.' And just opening up that possibilities of doing that. - CA6

Having someone like a career advisor outline the steps to achieving a job supports proactive personality by showing them concrete steps they can take immediately. Consistent with prior work in sociology, outlining the steps from where individuals are now to where they want to be has been shown to support greater motivation and persistence among marginalized populations [80].

5.4.2 Seeking additional information. However, outlining these steps and directing job seekers to certain jobs is not an insignificant task. Career advisors also needed to walk the job seekers through how to research their career goals to see if they were even viable given the current job market conditions. Some of this research could include reaching out to people in the desired job 
and asking for "informational interviews." Career advisors helped job seekers identity who to reach out to, as well as how to reach out to them appropriately, which depends on the platform (e.g., email or Facebook), field, and relationship [61].

If you can get a candidate to find someone doing that job and ask a lot of really good questions, both positive and negative. You know, I mean knowing the negatives about an occupation is very, very valuable. - CA7

According to career advisors, because job seekers typically cannot jump right into their dream jobs after conducting this background work, they worked with job seekers to identify entry-level positions that could help them acquire the right skills for their ideal career. Often times, these positions required lateral moves or pay cuts. Career advisors helped individuals think through whether this was the right step and if it could take them closer to their ultimate goal.

He wants to be in IT security. For him, there are some health reasons why he had to make the change. But, it's not easy to break into the IT security field when you don't have any experience in that field. If you're self-taught, even if you get a certification, you're still looked at as entry level. He's doing a stepping stone. He's taken a job at Best Buy on the Geek Squad, which is below what he'd like to earn. But, it might turn out to be a good stepping stone for him. - CA1

This focus on what to do "right now" encourages proactivity by helping job seekers constantly move forward. Career advisors promoted a proactive personality by helping job seekers identify, plan out, and take action towards future goals.

\subsection{Feelings of Stigma}

While we did not find evidence of fostering critical consciousness, we did see career advisors working a great deal to mitigate feelings of stigma associated with being a marginalized job seeker. Unlike critical consciousness, mitigating feelings of stigma does not point out structural inequalities or motivate political action, but helps job seekers acknowledge personal setbacks as obstacles to overcome and learn from. Unlike addressing economic conditions, mitigating feelings of stigma does not create or change one's economic opportunities. Similar to social support and proactive personality, mitigating feelings of stigma involves providing encouragement, but primarily involves the work of re-framing and reflecting on one's existing socio-economic situation. For instance, a career advisor, who was an ex-offender himself, described a speech he reiterates to ex-offenders.

'Everybody in this group has a big advantage over the rest of population.... We who have paid a big price for a bad decision, we know a lot more than a lot of people do. The offender, when given the opportunity, can be the best employee'...Invariably people, the offenders, tell me they're not afraid of interviewing anymore. They're not afraid of having a background. - $C A 3$

This way of reframing one's criminal background as an asset motivates returning citizens to stick with the job search process. Another career advisor described how he works to reduce stigma around applying for cash assistance. In one case, he encouraged a client to apply for funding to cover college tuition costs, expressing he would be a role model for others facing similar challenges in the community.

I kind of had to talk him into being into the program, because I'm like, 'You could be a success story.' It's not the typical person you're thinking applying for cash assistance. It could be anyone. If [I] was fired today, I could be applying for cash assistance. It could be any of us. - CA5 
Career advisors also encourage their clients to reflect on their existing assets. For instance, marginalized job seekers might have the tools and ability to apply to open positions, but personal and public perceptions often stop them from filling out and turning in applications. While marginalized job seekers may not have a strong professional network, previous work finds that they are able to utilize social media to find out critical information about potential jobs [101]. Career advisors play an important role in helping clients overcome these internal barriers by helping them re-frame and reflect on personal setbacks.

\section{DISCUSSION}

Previous work highlights shortcomings of existing employment support tools in serving marginalized job seekers, citing high barrier to entry and low transparency as challenges to securing work through online means $[31,37,58,59]$. Our work extends existing literature by providing the perspective of business service coordinators and career advisors who are trained in supporting marginalized job seekers. To address our second research question: How might the work of employment centers inform implications for designing employment support tools that are more inclusive to marginalized job seekers?, we use the Psychology of Working Theory and our findings from career advisors and business services coordinators (Table 1). We also propose applying critical consciousness to CSCW research on employment, a gap identified in our related work and via our findings, to challenge the systems and inequalities that marginalized job seekers experience to support efforts to securing decent work. Our recommendation echos (1) calls from researchers who propose applying feminist $\mathrm{HCI}$, critical race theory, and social justice-oriented [7, 39, 76] approaches to design; and (2) an ongoing call to create more egalitarian workplaces both online and offline [11, 43, 51, 55, 67].

\subsection{Extending employment support tools to address economic conditions, social support, and proactive personality}

Table 1 offers ways to extend existing digital technologies to address moderators to securing decent work. While we turn to past HCI and CSCW literature for recommendations, how to carry them out is less discussed and thus, an opportunity for the field. We propose new ideas for technology and identify ways for coordination between existing tools and local organizations in order to create a more supportive ecosystem for marginalized job seekers.

6.1.1 Addressing Challenges in Economic Conditions. Past researchers presented opportunities for work environments to be more inclusive to the various barriers marginalized job seekers face (e.g., homelessness, criminal background, lack of transportation and education). Business services coordinators worked with employers to determine fair and competitive wages, develop transportation programs, and write more welcoming job calls. Career advisors would work directly with job seekers to apply to benefits that employers may not be able to supply themselves, such as cash assistance to help pay for a car loan or education programs. Together, business services coordinators and career advisors, were able to recognize what made certain positions more inclusive towards marginalized job seekers, suggesting opportunities for employment support tools to detect and protect against discrimination. For example, sites like Indeed and LinkedIn could identify whether certain populations (e.g., racial and ethnic groups or genders) are disproportionately viewed or hired or not.

Employment sites like Glassdoor allow employees to provide anonymous reviews of companies and submit and view employee salaries to maintain a fair and equitable work environment. Such sites enable job seekers to give a voice to employee work conditions and understand whether job seeker assistance is available. However, to facilitate the role of business services coordinators, similar sites could support employers who wish to provide decent work. For example, systems 
Table 1. How career advisors and business services coordinators buffered and moderated the affect of marginalization and economic constraints on decent work, and opportunities for CSCW to do so.

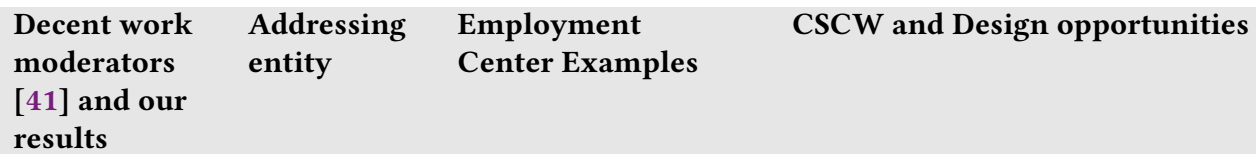

Economic

Career

Conditions

Advisors

Business

Services

Coordinators
Connected job seekers to external resources specific to their needs

Worked with employers to prepare more inclusive job calls and working conditions
- Detect and protect against discrimination (e.g., ML technologies to detect discriminatory language in job adds prior to posting)

- Promote inclusivity and decent work conditions (e.g., Worker-centered rating systems that recognize inclusive and fair employers, like [63])

- Foster connections with local support organizations (e.g., interfaces that allow for as-needed communication with local volunteers)

- Create programs and platforms addressing common needs (e.g., alternative gig platforms that provide affordable/free carpool matching)

$\begin{array}{ll}\text { Social } & \text { Career } \\ \text { Support } & \text { Advisors }\end{array}$

Provided encouragement in applying to external resources
- Provide more step-by-step guidance in applying to public benefits, writing cover letters, resumes, etc. (e.g., intelligent tutors for job application systems, [28, 30, 33, 61])

\section{Proactive Personality}

Helped clients strategize immediate next steps and prepare for longer-term career goals
- Support the exploration of new job opportunities [29], and career development opportunities (e.g., peer instruction in online freelancing, [11, 91])

- Suggest alternate employment pathways [34]

- Assist in the process of contacting employers directly (i.e., [61])

$\begin{aligned} & \text { Critical } \\ & \text { Consciousness }\end{aligned}$
N/A N/A

- Acknowledge job search inequalities and create spaces for interrogation

- Empower job seekers to take action, learn together, and create or participate in new forms of work (e.g., entrepreneurship, worker-owned cooperatives [60])

\begin{tabular}{|c|c|c|c|}
\hline Mitigating & Career & Supported re-framing & - Incorporate stigma-reducing language \\
\hline Stigma & Advisors & $\begin{array}{l}\text { and reflecting on } \\
\text { personal setbacks }\end{array}$ & $\begin{array}{l}\text { - Provide encouragement throughout the on- } \\
\text { line job search process } \\
\text { - Foster inclusive relationships with peers fac- } \\
\text { ing similar challenges }\end{array}$ \\
\hline
\end{tabular}


could analyze average wages for certain positions and recommend to an employer the need to increase their hourly rates to be competitive and minimize turnover; such actions could lead to better working conditions.

Building on previous work describing how marginalized job seekers use social media [101], employment sites could compile information across various factors, like treatment of returning citizens and pregnant women, and highlight those that rank higher among its workers. While companies are highlighted for allowing flexible work hours or being family friendly, many are not promoted based on their treatment of people who experience marginalization and oppressed groups. Our findings also highlight how employment centers partnered with external organizations to build employment support programs. For instance, career advisors worked with local courts and criminal justice system to hold annual expungement fairs as a way to help job seekers with criminal backgrounds clear their records. However, publishing records of criminal history online is considered lawful, regardless of past expungement and poses a risk to people with expunged criminal records [56]. While technology alone is insufficient ${ }^{2}$, designers of employment support tools might consider integration of online reputation management services (e.g., like BrandYourself ${ }^{3}$ ) to make online criminal records less salient or remind employers that such information might be invalid.

6.1.2 Extending Social Support. Our findings revealed that career advisors helped to moderate the lack of social support by providing encouragement in applying to public benefits, writing job applications, and dealing with rejections. Dillahunt et al. found in their review of employment support tools that some interventions help job seekers use their existing social connections to find jobs and new connections, thus building their social capital [33]. However, sites like LinkedIn rely on individuals who have existing professional social networks. In fact, Dillahunt et al. found that a conceptualized tool, "VouchforMe," a LinkedIn-like application that provided a way for individuals to "vouch" for others' skills, was least preferred by marginalized job seekers because it required them to have outside networks [33]. These authors found that another proposed social tool called "WeCanDoIt', an online support group where job seekers experiencing similar circumstances could support one another in their job search by sharing tips [33], was reviewed more favorably among job seekers experiencing marginalization because it assisted them in connecting and mobilizing with supportive peers. "WeCanDoIt" was conceptualized to serve a role very similar to that of career advisors in their support of returning citizens.

While most employment tools aim to match job seekers with employers, which is at the core of finding employment, career advisors provided marginalized job seekers with a type of social support currently unavailable when completing employment applications online. They served in care and empowerment roles, which can be seen through organizations like the National Association for the Advancement of Returning Citizens (NAARC), tailored training programs [78], and even in online Facebook Groups [62]. Future employment applications could focus on similar forms of care and empowerment for marginalized job seekers.

6.1.3 Extending Proactive Personalities. Arguably, job seekers who seek out support from employment organizations demonstrate a certain level of proactiveness. We found that career advisors contributed to their proactive personalities by helping job seekers to strategize their immediate next steps and to prepare for longer-term career goals. Tools like SkillsIdentifier [29], DreamGigs [34], and IntroAssist [61], which have been implemented by HCI and CSCW researchers, support

\footnotetext{
${ }^{2}$ Ensuring complete digital expungement requires legal intervention, changes in social norms, and changes in market forces for such information [56].

${ }^{3}$ https://brandyourself.com/about (last accessed January 14, 2021)
} 
the exploration of new job opportunities, suggest alternative pathways to employment, and assist in the process of contacting employers directly. However, these tools still require, to some extent, some person-to-person guidance, especially for those who are less familiar with digital technologies. Nevertheless, such concepts could be easily implemented into existing employment tools such as Indeed, LinkedIn, Facebook Groups, and Massive Open Online Courses [36] to support marginalized job seekers who are active online. In fact, work by Blaising et al. explores how online freelancing tools foster career domain exploration and transition, provide training, and offer opportunities to build a reputation and for skills transfer [11].

\subsection{Designing to Mitigate Feelings of Stigma in Employment}

Those who face greater economic constraints and marginalization often struggle with experiencing stigma in the job search process. Stigma refers to any persistent individual or group attribute which evokes negative or punitive responses [68], and reduces self worth and self valuations [93]. In various interviews, career advisors spoke of how job seekers had little faith in being hired due to one or more stigmatizing factors.

Our results showed that career advisors used techniques to mitigate feelings of stigma, which was not a moderator mentioned in the original PWT theory. Career advisors helped job seekers reframe and reflect on their personal setbacks, while business services coordinators encouraged employers in hiring a diverse workforce, which could also increase contact with other members of stigmatized groups. They also helped to raise awareness of the different ways in which disabilities might exist. Such interventions could aid in reducing feelings of stigma in job seekers by helping to bust myths and challenge negative stereotypes with factual information, cognitive reframing, and disclosure promotion [93]. Understanding the role digital interventions can have for addressing stigma is a new area of research [93] and is one that HCI can contribute to based on the field's aim to understand how to conduct research among stigmatized populations [2, 73]. In fact, future interventions in job posting platforms, like Indeed, could help employers incorporate language that reduce feelings of stigma among those applying, and provide encouragement throughout the online job search process by highlighting programs and policies that make the workplace more inclusive. Such sites could also build online communities (e.g., like "WeCanDoIt" [33]), among peers who face similar challenges, which has shown to foster socially supportive relationships and reduce feelings of stigma $[1,71]$.

\subsection{Opportunities to Engage in Critical Consciousness}

Beyond aims to reduce feelings of stigma, the Psychology of Working Theory suggests job seekers must reflect on their marginalization and economic constraints at a much deeper level. Rather than just reframing and reflecting on one's situation, PWT argues for the importance of critical consciousness-one's ability to recognize and overcome socio-political barriers [26]. This practice requires going beyond just recognizing that one's socio-economic contexts will lead to greater challenges and will require extra effort to overcome. Rather, critical consciousness involves questioning the overarching socio-economic system and mobilizing to change the state of the world. While we did not find evidence of career advisors and business services coordinators supporting critical consciousness, we find it to be a critical next step.

Critical consciousness has not been as extensively discussed in career development literature. Drawing from critical pedagogy [47], support for critical consciousness would have required a focus on how privilege is sustained and how oppression creates disproportional levels of unemployment, crime, and marginalization. To address this gap, we suggest engaging in critical questioning of the state of employment support tools. At a high-level, the employment center acknowledges and aims to address the information asymmetries that exist between job seekers and the employers.

Proc. ACM Hum.-Comput. Interact., Vol. 5, No. CSCW2, Article 324. Publication date: October 2021. 
They further facilitate the matching process between job seekers and employers and could reduce job-related challenges among employers and job seekers who experience marginalization. While addressing information asymmetries does aim to address a power imbalance, a critical consciousness lens from the perspective of the employment center, might have led to more critical questioning. For example, are certain "soft skills" truly an issue or is the requirement to develop such skills rooted in forms of social injustice? For instance, suggesting the development of time management skills to a job seeker who is frequently late would be unproductive if transportation is unavailable or unpredictable to them. Can such a line of questioning be explored in the design of such systems? While this might be an unconventional approach among employment centers, such approaches have been found to be successful among marginalized youth in their career development and education $[19,25,53,98]$

It is possible that from the perspective of a job seeker, the stress of living paycheck to paycheck leaves little bandwidth to challenge the status quo [46]. Guy Standing describes this class of people as 'the precariat,' or those who face constant employment insecurity and move in and out of jobs that add little meaning to their lives [89]. He identifies three factions: the "atavists" (a group with no college degree who begrudgingly reminisce on their past and recall how their college uneducated parents could secure occupations like automotive and steel workers), the "nostalgics" (primarily migrant, minorities and refugees who keep their heads down to survive and have no true sense of home), and the "progressives" (those who exit college in debt and are left searching for jobs). The majority of the job seekers described in our results arguably represent nostalgics and perhaps some atavists given the impact of the significant employment reduction in the manufacturing industry. Career advisors and business services coordinators described how many of their constituents were primarily concerned with finding a job that could provide an immediate paycheck, whether or not it aligned with their interests or long-term values. Standing describes how people in the precariat are less likely to have occupational narratives to give their lives meaning-in addition to this, they often lack a unified identity, which could reduce opportunities for shared reflection and mobilization [89]. Shared reflection and mobilization are key outcomes of engaging in critical consciousness [41]. Thus, critical consciousness development might serve as a next step for career advisors and business services coordinators if and when their constituents sense some level of employment stability. For now, career advisors and business service coordinators might prioritize the many urgent needs described, which were an effect of marginalization and economic conditions.

Duffy et al. propose interventions to mobilize populations who struggle to make meaning of systemic factors impacting their work lives [41]. They suggest providing evidenced-based ideas that might lead to such mobilization and helping individuals to advocate for decency and equity. Perhaps business services coordinators could coordinate with local worker cooperatives, which exist as a way to combat growing economic inequality [87]. Employees would equally own and operate these cooperatives and earn money from the profits of their labor. In fact, there might be opportunities for technologies to support the creation of such cooperatives among such employment organizations or marginalized job seekers themselves.

\section{CONCLUSION}

We present the results of an empirical study consisting of 21 semi-structured interviews with employment center staff-career advisors and business services coordinators. Our aim was to understand their techniques to buffer the effects of marginalization and economic constraints on acquiring decent work. Our findings confirm the severe impact of economic conditions such as homelessness and transportation scarcity [31, 37, 58,59], which serve as barriers to marginalized job seekers. While technology alone cannot address these challenges, our research outlines significant room for improvement. Thus, building on our findings, we highlight opportunities and provide 
design implications for future technologies and platforms to provide support beyond resume review or interview feedback [33], and matching job seekers to open positions. Our work is particularly timely given the economic and employment impact caused by the COVID-19 pandemic-the economic brunt of which is felt by marginalized job seekers.

\section{ACKNOWLEDGMENTS}

We are grateful to our community partners and participants for their insights and support. We appreciate early feedback from Mustafa Naseem, Cliff Lampe, Alex Lu, Joey Hsiao and the rest of the Social Innovations Group. We are grateful to Matt Diemer who also provided us with a deeper understanding of PWT and CC. We also thank our anonymous reviewers for their thoughtful feedback. This work was supported by the NSF award IIS-1717186.

\section{REFERENCES}

[1] Nazanin Andalibi. 2020. Disclosure, Privacy, and Stigma on Social Media: Examining Non-Disclosure of Distressing Experiences. ACM Transactions on Computer-Human Interaction (TOCHI) 27, 3 (2020), 1-43.

[2] Nazanin Andalibi, Margaret E. Morris, and Andrea Forte. 2018. Testing waters, sending clues: Indirect disclosures of socially stigmatized experiences on social media. Proceedings of the ACM on Human-Computer Interaction 2, CSCW (2018), 19.

[3] Anonymous 2019. Anonymous. Anonymous. Anonymous

[4] Ira Anjali Anwar, Joyojeet Pal, and Julie S. Hui. 2020. Watched, but Moving: Platformization of Beauty Work and Its Gendered Mechanisms of Control. Proc. ACM Hum.-Comput. Interact. 4, CSCW3, Article 250 (Dec. 2020), 19 pages. https://doi.org/10.1145/3432949

[5] Kelsey .L Autin, Ryan D. Duffy, Caitlin J. Jacobson, Kabeel M. Dosani, Dominique Barker, and Elizabeth M. Bott. 2018. Career development among undocumented immigrant young adults: A psychology of working perspective. Fournal of Counseling Psychology 65, 5 (2018), 605.

[6] Seyram Avle, Julie S. Hui, Silvia Lindtner, and Tawanna R. Dillahunt. 2019. Additional Labors of the Entrepreneurial Self. Proceedings of the ACM on Human-Computer Interaction 3, CSCW (2019), 1-24.

[7] Shaowen Bardzell. 2010. Feminist HCI: Taking Stock and Outlining an Agenda for Design. In Proceedings of the SIGCHI Conference on Human Factors in Computing Systems. Association for Computing Machinery, New York, NY, USA, 1301-1310. https://doi.org/10.1145/1753326.1753521

[8] Thomas S. Bateman and J. Michael Crant. 1993. The proactive component of organizational behavior: A measure and correlates. Fournal of organizational behavior 14, 2 (1993), 103-118.

[9] Seth G. Benzell, Laurence J. Kotlikoff, Guillermo LaGarda, and Jeffrey D. Sachs. 2015. Robots are us: Some economics of human replacement. Technical Report. National Bureau of Economic Research.

[10] Linda Birt, Suzanne Scott, Debbie Cavers, Christine Campbell, and Fiona Walter. 2016. Member checking: a tool to enhance trustworthiness or merely a nod to validation? Qualitative health research 26, 13 (2016), 1802-1811.

[11] Allie Blaising, Yasmine Kotturi, Chinmay Kulkarni, and Laura Dabbish. 2021. Making It Work, or Not: A Longitudinal Study of Career Trajectories Among Online Freelancers. Proc. ACM Hum.-Comput. Interact. 4, CSCW3, Article 226 (Jan. 2021), 29 pages. https://doi.org/10.1145/3432925

[12] David L. Blustein. 2013. The psychology of working: A new perspective for career development, counseling, and public policy. Routledge, Mahwah, NJ, USA.

[13] David L. Blustein. 2019. The importance of work in an age of uncertainty: The eroding work experience in America. Oxford University Press, Oxford, UK.

[14] David L. Blustein, Maureen E. Kenny, Annamaria Di Fabio, and Jean Guichard. 2019. Expanding the impact of the psychology of working: Engaging psychology in the struggle for decent work and human rights. fournal of Career Assessment 27, 1 (2019), 3-28.

[15] Nina Boulus-Rødje. 2018. In search for the perfect pathway: supporting knowledge work of welfare workers. Computer Supported Cooperative Work (CSCW) 27, 3-6 (2018), 841-874.

[16] Bureau of Labor Statistics 2018 (accessed March 15, 2019). Labor Force Statistics from the Current Population Survey. Bureau of Labor Statistics. https:/www.bls.gov/web/empsit/cpseea10.htm

[17] Bureau of Labor Statistics 2018 (accessed March 15, 2019). Unemployment rates and earnings by educational attainment. Bureau of Labor Statistics. https://www.bls.gov/emp/chart-unemployment-earnings-education.htm

[18] Bureau of Labor Statistics 2018 (accessed March 27, 2019). Economic News Release: Persons with a Disability: Labor Force Characteristics Summary. Bureau of Labor Statistics. https://www.bls.gov/news.release/disabl.nr0.htm 
Implications for Supporting Marginalized Job Seekers:

Lessons from Employment Centers

[19] Dorinda J. Carter. 2008. Cultivating a critical race consciousness for African American school success. Educational foundations 22 (2008), 11-28.

[20] Karen Chapple. 2005. Promising futures: workforce development and upward mobility in information technology. Berkeley, Calif: Institute of Urban and Regional Development. University of California at Berkeley.

[21] Karen Chapple. 2006. Networks to Nerdistan: The Role of Labor Market Intermediaries in the Entry-level IT Labor Market. International Journal of Urban and Regional Research 30, 3 (2006), 548-563.

[22] S. Cohen. 1984. Social support, stress, and the buffering hypothesis : A theoretical analysis. Handook of psychology and health (Vol.4) 4, 1 (1984), 253-267. https://ci.nii.ac.jp/naid/10004939175/en/

[23] Sheldon Cohen and Thomas A. Wills. 1985. Stress, social support, and the buffering hypothesis. Psychological bulletin 98, 2 (1985), 310.

[24] Elizabeth R. Cole. 2009. Intersectionality and research in psychology. American psychologist 64, 3 (2009), 170.

[25] Matthew A. Diemer. 2009. Pathways to Occupational Attainment Among Poor Youth of Color: The Role of Sociopolitical Development. The Counseling Psychologist 37, 1 (2009), 6-35. https://doi.org/10.1177/0011000007309858 arXiv:https://doi.org/10.1177/0011000007309858

[26] Matthew A. Diemer and David L. Blustein. 2006. Critical consciousness and career development among urban youth. Journal of vocational behavior 68, 2 (2006), 220-232.

[27] Matthew A. Diemer and Chueh-An Hsieh. 2008. Sociopolitical development and vocational expectations among lower socioeconomic status adolescents of color. The Career Development Quarterly 56, 3 (2008), 257-267.

[28] Tawanna R. Dillahunt, Nishan Bose, Suleman Diwan, and Asha Chen-Phang. 2016. Designing for Disadvantaged Job Seekers: Insights from Early Investigations. In Proc. of the 2016 ACM Conference on Designing Interactive Systems (Brisbane, QLD, Australia) (DIS '16). ACM, New York, NY, USA, 905-910. https://doi.org/10.1145/2901790.2901865

[29] Tawanna R. Dillahunt and Chiao-Yin Hsiao. 2021. SkillsIdentifier: A Tool to Promote Career Identity and Self-efficacy Among Underrepresented Job Seekers. In Proceedings of the 54th Hawaii International Conference on System Sciences. Hawaii International Conference on System Sciences, Honolulu, HI, USA, 4848.

[30] Tawanna R. Dillahunt and Joey Chiao-Yin Hsiao. 2020. Positive Feedback and Self-Reflection: Features to Support Self-Efficacy among Underrepresented Job Seekers. In Proceedings of the 2020 CHI Conference on Human Factors in Computing Systems (Honolulu, HI, USA) (CHI '20). Association for Computing Machinery, New York, NY, USA, 1-13. https://doi.org/10.1145/3313831.3376717

[31] Tawanna R. Dillahunt, Vaishnav Kameswaran, Linfeng Li, and Tanya Rosenblat. 2017. Uncovering the values and constraints of real-time ridesharing for low-resource populations. In Proceedings of the 2017 CHI Conference on Human Factors in Computing Systems. ACM, New York, NY, USA, 2757-2769.

[32] Tawanna R. Dillahunt, Vaishnav Kameswaran, Desiree McLain, Minnie Lester, Delores Orr, and Kentaro Toyama. 2018. Entrepreneurship and the Socio-Technical Chasm in a Lean Economy. In Proceedings of the 2018 CHI Conference on Human Factors in Computing Systems (Montreal QC, Canada) (CHI '18). ACM, New York, NY, USA, Article 240, 14 pages. https://doi.org/10.1145/3173574.3173814

[33] Tawanna R. Dillahunt, Jason Lam, Alex Lu, and Earnest Wheeler. 2018. Designing Future Employment Applications for Underserved Job Seekers: A Speed Dating Study. In Proceedings of the 2018 Designing Interactive Systems Conference. ACM, New York, NY, USA, 33-44.

[34] Tawanna R. Dillahunt and Alex Lu. 2019. DreamGigs: Designing a Tool to Empower Low-Resource Job Seekers. In Proceedings of the 2019 CHI Conference on Human Factors in Computing Systems (Glasgow, Scotland Uk) (CHI '19). Association for Computing Machinery, New York, NY, USA, 1-14. https://doi.org/10.1145/3290605.3300808

[35] Tawanna R. Dillahunt and Amelia R. Malone. 2015. The Promise of the Sharing Economy Among Disadvantaged Communities. In Proceedings of the 33rd Annual ACM Conference on Human Factors in Computing Systems (Seoul, Republic of Korea) (CHI '15). ACM, New York, NY, USA, 2285-2294. https://doi.org/10.1145/2702123.2702189

[36] Tawanna R. Dillahunt, Sandy Ng, Michelle Fiesta, and Zengguang Wang. 2016. Do Massive Open Online Course Platforms Support Employability?. In Proceedings of the 19th ACM Conference on Computer-Supported Cooperative Work and Social Computing (San Francisco, California, USA) (CSCW '16). Association for Computing Machinery, New York, NY, USA, 233-244. https://doi.org/10.1145/2818048.2819924

[37] Tawanna R. Dillahunt and Tiffany C. Veinot. 2018. Getting there: Barriers and facilitators to transportation access in underserved communities. ACM Transactions on Computer-Human Interaction (TOCHI) 25, 5 (2018), 29.

[38] Lynn Dombrowski, Adriana Alvarado Garcia, and Jessica Despard. 2017. Low-Wage Precarious Workers' Sociotechnical Practices Working Towards Addressing Wage Theft. In Proceedings of the 2017 CHI Conference on Human Factors in Computing Systems (Denver, Colorado, USA) (CHI '17). ACM, New York, NY, USA, 4585-4598. https://doi.org/10. $1145 / 3025453.3025633$

[39] Lynn Dombrowski, Ellie Harmon, and Sarah Fox. 2016. Social Justice-Oriented Interaction Design: Outlining Key Design Strategies and Commitments. In Proceedings of the 2016 ACM Conference on Designing Interactive Systems (Brisbane, QLD, Australia) (DIS '16). Association for Computing Machinery, New York, NY, USA, 656-671. https:

Proc. ACM Hum.-Comput. Interact., Vol. 5, No. CSCW2, Article 324. Publication date: October 2021. 
//doi.org/10.1145/2901790.2901861

[40] Ryan D. Duffy, Blake A. Allan, Jessica W. England, David L. Blustein, Kelsey L. Autin, Richard P. Douglass, Joaquim Ferreira, and Eduardo JR. Santos. 2017. The development and initial validation of the Decent Work Scale. Fournal of counseling psychology 64, 2 (2017), 206.

[41] Ryan D. Duffy, David L. Blustein, Matthew A. Diemer, and Kelsey L. Autin. 2016. The psychology of working theory. fournal of Counseling Psychology 63, 2 (2016), 127.

[42] Ryan D. Duffy, Brandon L. Velez, Jessica W. England, Kelsey L. Autin, Richard P. Douglass, Blake A. Allan, and David L. Blustein. 2018. An examination of the Psychology of Working Theory with racially and ethnically diverse employed adults. Journal of Counseling Psychology 65, 3 (2018), 280.

[43] Ron Eglash, Audrey Bennett, Michael Lachney, and William Babbitt. 2020. Race-positive design: A generative approach to decolonizing computing. In Human factors in computing systems. ACM, New York, NY, USA, 1-7.

[44] Aaliyah El-Amin, Scott Seider, Daren Graves, Jalene Tamerat, Shelby Clark, Madora Soutter, Jamie Johannsen, and Saira Malhotra. 2017. Critical consciousness: A key to student achievement. Phi Delta Kappan 98, 5 (2017), 18-23.

[45] Virginia Eubanks. 2018. Automating inequality: How high-tech tools profile, police, and punish the poor. St. Martin's Press, New York, NY, USA.

[46] Brad Evans and Julian Reid. 2014. Resilient life: The art of living dangerously. John Wiley \& Sons.

[47] Paulo Freire. 2018. Pedagogy of the oppressed. Bloomsbury publishing USA, New York, NY, USA.

[48] Mel Fugate, Angelo J. Kinicki, and Blake E. Ashforth. 2004. Employability: A psycho-social construct, its dimensions, and applications. Fournal of Vocational behavior 65, 1 (2004), 14-38.

[49] Bryan Fuller Jr. and Laura E. Marler. 2009. Change driven by nature: A meta-analytic review of the proactive personality literature. Journal of vocational behavior 75, 3 (2009), 329-345.

[50] Maria Garrido, Joe Sullivan, and Andrew Gordon. 2010. Understanding the links between ICT skills training and employability: an analytical framework. In Proceedings of the 4th ACM/IEEE International Conference on Information and Communication Technologies and Development. ACM, Association for Computing Machinery, New York, NY, USA, 15.

[51] Christine Gerber and Martin Krzywdzinski. 2019. Brave new digital work? New forms of performance control in crowdwork. In Work and Labor in the Digital Age. Emerald Publishing Limited, Bingley, UK.

[52] Ilana Gershon. 2017. Down and out in the new economy: How people find (or don't find) work today. University of Chicago Press, Chicago, IL, USA.

[53] Shawn A. Ginwright. 2010. Black youth rising: Activism and radical healing in urban America. Teachers College Press, New York, NY, USA.

[54] Angela N. Gist. 2014. Managing unemployment: A comparative, critical ethnographic analysis of unemployment organizations. Ph.D. Dissertation. University of Missouri-Columbia.

[55] Mary L. Gray and Siddharth Suri. 2019. Ghost work: how to stop Silicon Valley from building a new global underclass. Houghton Mifflin Harcourt Publishing, New York, NY, USA.

[56] Eldar Haber. 2017. Digital expungement. Md. L. Rev. 77 (2017), 337.

[57] Gillian R. Hayes, V. Erick Custodio, Oliver L. Haimson, Kathy Nguyen, Kathryn E. Ringland, Rachel Rose Ulgado, Aaron Waterhouse, and Rachel Weiner. 2015. Mobile video modeling for employment interviews for individuals with autism. Journal of Vocational Rehabilitation 43, 3 (2015), 275-287.

[58] David G. Hendry, Norah Abokhodair, Rose Paquet Kinsley, and Jill Palzkill Woelfer. 2017. Homeless Young People, Jobs, and a Future Vision: Community Members' Perceptions of the Job Co-op. In Proceedings of the 8th International Conference on Communities and Technologies (Troyes, France) (C\&T '17). ACM, New York, NY, USA, 22-31. https: //doi.org/10.1145/3083671.3083680

[59] David G. Hendry, Jill Palzkill Woelfer, and Thuy Duong. 2017. U-District Job Co-op: constructing a future vision for homeless young people and employment. Information Technology \& People 30 (2017), 602-628. http://www. emeraldinsight.com/doi/full/10.1108/ITP-05-2015-0117

[60] Julie Hui, Nefer Ra Barber, Wendy Casey, Suzanne Cleage, Danny C Dolley, Frances Worthy, Kentaro Toyama, and Tawanna R Dillahunt. 2020. Community Collectives: Low-tech Social Support for Digitally-Engaged Entrepreneurship. In Proceedings of the $2020 \mathrm{CHI}$ Conference on Human Factors in Computing Systems. 1-15.

[61] Julie S. Hui, Darren Gergle, and Elizabeth M. Gerber. 2018. IntroAssist: A Tool to Support Writing Introductory Help Requests. In Proceedings of the 2018 CHI Conference on Human Factors in Computing Systems. ACM, New York, NY, USA, 22.

[62] Julie S. Hui, Kentaro Toyama, Joyojeet Pal, and Tawanna R. Dillahunt. 2018. Making a Living My Way: Necessitydriven Entrepreneurship in Resource-Constrained Communities. Proc. ACM Hum.-Comput. Interact. 2, CSCW, Article 71 (Nov. 2018), 24 pages. https://doi.org/10.1145/3274340

[63] Lilly C Irani and M Six Silberman. 2013. Turkopticon: Interrupting worker invisibility in amazon mechanical turk. In Proceedings of the SIGCHI conference on human factors in computing systems. 611-620. 
Implications for Supporting Marginalized Job Seekers:

Lessons from Employment Centers

[64] Louis S. Jacobson. 2009. Strengthening One-Stop Career Centers: Helping more unemployed workers find jobs and build skills. Brookings Institution Washington, DC, Washington, DC.

[65] Benjamin Jen, Jashanjit Kaur, Jonathan De Heus, and Tawanna R. Dillahunt. 2014. Analyzing employment technologies for economically distressed individuals. In Proceedings of the extended abstracts of the 32nd annual ACM conference on Human factors in computing systems. ACM, Association for Computing Machinery, New York, NY, USA, 1945-1950.

[66] Pascale Joassart-Marcelli and Alberto Giordano. 2006. Does local access to employment services reduce unemployment? A GIS analysis of one-stop career centers. Policy Sciences 39, 4 (2006), 335-359.

[67] Hannah Johnston, Chris Land-Kazlauskas, et al. 2018. Organizing on-demand: Representation, voice, and collective bargaining in the gig economy. Conditions of work and employment series 94 (2018), 1-47.

[68] Yu-Ming Lai, CPH Hong, and Cornelia YI Chee. 2001. Stigma of mental illness. Singapore medical journal 42, 3 (2001), 111-114.

[69] Ning Li, Jian Liang, and J. Michael Crant. 2010. The role of proactive personality in job satisfaction and organizational citizenship behavior: A relational perspective. Journal of applied psychology 95, 2 (2010), 395.

[70] Yvonna S Lincoln. 2007. Naturalistic inquiry. The Blackwell Encyclopedia of Sociology (2007).

[71] Danielle Lottridge, Nazanin Andalibi, Joy Kim, and Jofish Kaye. 2019. " Giving a little'ayyy, I feel ya'to someone's personal post" Performing Support on Social Media. Proceedings of the ACM on Human-Computer Interaction 3, CSCW (2019), 1-22.

[72] Alex Lu, Jason Brill, and Tawanna R. Dillahunt. 2018. DreamGigs: A. In Companion of the 2018 ACM Conference on Computer Supported Cooperative Work and Social Computing (Jersey City, NJ, USA) (CSCW '18). ACM, New York, NY, USA, 317-320. https://doi.org/10.1145/3272973.3274086

[73] Juan F. Maestre, Elizabeth V. Eikey, Mark Warner, Svetlana Yarosh, Jessica Pater, Maia Jacobs, Gabriela Marcu, and Patrick C. Shih. 2018. Conducting Research with Stigmatized Populations: Practices, Challenges, and Lessons Learned. In Companion of the 2018 ACM Conference on Computer Supported Cooperative Work and Social Computing (Jersey City, NJ, USA) (CSCW '18). ACM, New York, NY, USA, 385-392. https://doi.org/10.1145/3272973.3273003

[74] Judith Mariscal, Luis Hernando Gutierrez, and Antonio José Junqueira Botelho. 2009. Employment and Youth Inclusion into the Labor Force via Training in Information and Communication Technologies (ICTs): The Cases of Brazil, Colombia, and Mexico. Information technologies \& international development 5, 2 (2009), 19-30.

[75] Bureau of Labor Statistics. 2018 (accessed March 15, 2019). . Labor force characteristics by race and ethnicity, 2017. https://www.bls.gov/opub/reports/race-and-ethnicity/2017/home.htm

[76] Ihudiya Finda Ogbonnaya-Ogburu, Angela D.R. Smith, Alexandra To, and Kentaro Toyama. 2020. Critical Race Theory for HCI. In Proceedings of the 2020 CHI Conference on Human Factors in Computing Systems. Association for Computing Machinery, New York, NY, USA, 1-16. https://doi.org/10.1145/3313831.3376392

[77] Ihudiya Finda Ogbonnaya-Ogburu, Kentaro Toyama, and Tawanna R. Dillahunt. 2018. Returning Citizens' Job Search and Technology Use: Preliminary Findings. In Companion of the 2018 ACM Conference on Computer Supported Cooperative Work and Social Computing (Jersey City, NJ, USA) (CSCW'18). ACM, New York, NY, USA, 365-368. https://doi.org/10.1145/3272973.3274098

[78] Ihudiya Finda Ogbonnaya-Ogburu, Kentaro Toyama, and Tawanna R. Dillahunt. 2019. Towards an Effective Digital Literacy Intervention to Assist Returning Citizens with Job Search. In Proceedings of the 2019 CHI Conference on Human Factors in Computing Systems. ACM, New York, NY, USA, 1-12.

[79] Occupational Information Network (O*NET). [n.d.]. Summary Report for: 21-1012.00 - Educational, Guidance, and Career Counselors and Advisors. https://www.onetonline.org/link/summary/21-1012.00

[80] Daphna Oyserman and Mesmin Destin. 2010. Identity-based motivation: Implications for intervention. The Counseling Psychologist 38, 7 (2010), 1001-1043.

[81] Noopur Raval and Paul Dourish. 2016. Standing Out from the Crowd: Emotional Labor, Body Labor, and Temporal Labor in Ridesharing. In Proceedings of the 19th ACM Conference on Computer-Supported Cooperative Work \& Social Computing (San Francisco, California, USA) (CSCW'16). ACM, New York, NY, USA, 97-107. https://doi.org/10.1145/ 2818048.2820026

[82] Ken Roberts. 2012. Career development among the lower socioeconomic strata in developed countries. Career development: Global issues and challenges (2012), 29-43.

[83] Johnny Saldaña. 2015. The Coding Manual for Qualitative Researchers (3 ed.). SAGE Publications Ltd, Washington, DC. 368 pages.

[84] Niloufar Salehi and Michael S. Bernstein. 2018. Ink: Increasing Worker Agency to Reduce Friction in Hiring Crowd Workers. ACM Transactions on Computer-Human Interaction (TOCHI) 25, 2 (2018), 10.

[85] Mark L. Savickas and Erik J. Porfeli. 2012. Career Adapt-Abilities Scale: Construction, reliability, and measurement equivalence across 13 countries. Fournal of vocational behavior 80, 3 (2012), 661-673.

[86] Kristin S. Seefeldt. 2016. Abandoned families: Social isolation in the twenty-first century. Russell Sage Foundation, New York, NY, USA.

Proc. ACM Hum.-Comput. Interact., Vol. 5, No. CSCW2, Article 324. Publication date: October 2021. 
[87] Alana Semuels. 2015. Getting Rid of Bosses: Can a Company Succeed If No One is in Charge? https://www.theatlantic. com/business/archive/2015/07/no-bosses-worker-owned-cooperatives/397007/ [Online; posted 8-July-2015].

[88] Stephanie A. Shields. 2008. Gender: An intersectionality perspective. Sex roles 59, 5-6 (2008), 301-311.

[89] Guy Standing. 2011. The Precariat: The New Dangerous Class. Bloomsbury Academic, New York, NY.

[90] Will Sutherland and Mohammad Hossein Jarrahi. 2017. The Gig Economy and Information Infrastructure: The Case of the Digital Nomad Community. Proc. ACM Hum.-Comput. Interact. 1, CSCW, Article 97 (Dec. 2017), 24 pages. https://doi.org/10.1145/3134732

[91] Ryo Suzuki, Niloufar Salehi, Michelle S. Lam, Juan C. Marroquin, and Michael S. Bernstein. 2016. Atelier: Repurposing expert crowdsourcing tasks as micro-internships. In Proceedings of the 2016 CHI conference on human factors in computing systems. ACM, New York, NY, USA, 2645-2656.

[92] Kevin A. Tate, Kathleen M. Fallon, Elaine J. Casquarelli, and Laura Reid Marks. 2014. Opportunities for Action: Traditionally Marginalized Populations and the Economic Crisis. Professional Counselor 4, 4 (2014), 285-302.

[93] Neil Thomas, Bronte McLeod, Nev Jones, and Jo-Anne Abbott. 2015. Developing internet interventions to target the individual impact of stigma in health conditions. Internet Interventions 2, 3 (2015), 351-358.

[94] David M. Tokar and Kevin P. Kaut. 2018. Predictors of decent work among workers with Chiari malformation: An empirical test of the psychology of working theory. fournal of Vocational Behavior 106 (2018), 126-137.

[95] Raymond Torres. 2008. World of Work Report 2008: Income inequalities in the age of financial globalization. International Labour Office Geneva, Geneve, Switzerland.

[96] Carl E. Van Horn. 2014. Working scared (or not at all): The lost decade, great recession, and restoring the shattered American dream. Rowman \& Littlefield, Lanham, MD, USA.

[97] Sanne Verbaan, Clair Aldington, Roisin McNaney, and Jayne Wallace. 2018. Potentials of HCI for Prisons and Incarcerated Individuals. In Extended Abstracts of the 2018 CHI Conference on Human Factors in Computing Systems (Montreal QC, Canada) (CHI EA '18). ACM, New York, NY, USA, Article SIG17, 4 pages. https://doi.org/10.1145/ 3170427.3185367

[98] Roderick J. Watts, Matthew A. Diemer, and Adam M. Voight. 2011. Critical consciousness: Current status and future directions. New directions for child and adolescent development 2011, 134 (2011), 43-57.

[99] Roderick J. Watts, Derek M. Griffith, and Jaleel Abdul-Adil. 1999. Sociopolitical development as an antidote for oppression-theory and action. American journal of community psychology 27, 2 (1999), 255-271.

[100] Mark West and Maria Garrido. 2008. Bridging the e-skills gap in Central and Eastern Europe: The growth of e-skills and employability initiatives in the newly expanded European Union. Technical Report. Technology \& Social Change Group (TASCHA).

[101] Earnest Wheeler and Tawanna R. Dillahunt. 2018. Navigating the Job Search as a Low-Resourced Job Seeker. In Proceedings of the 36th Annual ACM Conference on Human Factors in Computing Systems (Montreal, QC, Canada) (CHI '18). ACM, New York, NY, USA, 10 pages. https://doi.org/10.1145/3173574.3173622

Received January 2021; revised April 2021; accepted May 2021 